\title{
Indole Glucosinolates Exhibits Anti-Inflammatory Effect on Ehrlich Ascites Carcinoma Cells through Modulation of Inflammatory Markers and miRNAs
}

\section{Ayah Z. Salem}

Ain Shams University

Dalia Medhat

National Research Centre

Shadia A. Fathy

Ain Shams University

Mohamed R. Mohamed

Ain Shams University

\section{Zakaria El-Khayat}

National Research Centre

Sherien M. El-Daly ( $\nabla$ sm.el-daly@nrc.sci.eg )

National Research Centre https://orcid.org/0000-0003-0049-8606

\section{Research Article}

Keywords: Inflammation, Nuclear factor-kB, indole-3-carbinol, 3,3-diindolylmethane, 5-Fluorouracil, Ehrlich ascites carcinoma, miR-21, miR-31.

Posted Date: June 28th, 2021

DOI: https://doi.org/10.21203/rs.3.rs-529153/v1

License: (c) (1) This work is licensed under a Creative Commons Attribution 4.0 International License.

Read Full License 


\section{Abstract}

Background: Nuclear factor-kB (NF-kB) is the major link between inflammation and cancer. Natural agents that inhibit this pathway are essential in attenuating inflammation induced by cancer and/or induced by chemotherapeutic drugs. A high intake of Brassicaceae vegetables is linked to modulating essential pathways related to chronic diseases. In the present study, we investigated the anti-proliferative and anti-inflammatory effect of glucosinolates indoles; indole-3-carbinol (I3C) and 3,3-diindolylmethane (DIM) on the inflammatory biomarkers and miRNAs controlling the NF-KB pathway.

Methods and Results: inoculation of Ehrlich ascites carcinoma (EAC) cells in female albino mice resulted in a marked increase in packed cell volume and a significant increase in the level of several cytokines and inflammatory biomarkers (NF-KB IL-6, IL-1b, TNF-a, and NO). A significant elevation in the inflammatorymedicated miRNAs (miR-31 and miR-21) was also detected. Treatment with 5-Fluorouracil (5-FU) significantly reduces packed cell volume and the viable cell count. However, it was accompanied by a significant increase in the levels of inflammatory markers and the expression of miR-31 and miR-21. Although treatment with indoles significantly reduced the packed cell volume and the viable cell count, their most prominent effect was the marked reduction of all inflammatory biomarkers compared to both EAC untreated group and the EAC group treated with 5-FU. Moreover, their anti-inflammatory effect was modulated by a significant decrease in miR-31 and miR-21.

Conclusion: Our findings revealed that $\mathrm{I} 3 \mathrm{C}$ and DIM have a strong anti-inflammatory effect, implying that their use as a co-treatment with chemotherapeutic drugs could effectively improve the anti-tumor effect of chemotherapies.

\section{Introduction}

Cancer is a growing health problem worldwide. The high increase in life expectancy, rising urbanization, and subsequent environmental factors, including lifestyle, have all contributed to the rise of cancer incidence. More than two-thirds of human cancers are thought to be preventable with appropriate lifestyle changes [1].

Chronic inflammation is implicated in the development and progression of different types of cancer. A variety of soluble factors and cellular signaling events play a crucial role in inflammation. The most important signaling pathway involved in the initiation and amplification of inflammatory responses is the one that leads to nuclear factor- KB (NF-KB) activation [2]. Since NF-KB regulates several genes that are activated in response to inflammation, it may play a vital role in the inflammatory response to infection and tissue injury. The transcription factors in the NF-KB family control the expression of genes that code for cytokines (like interleukin - 6 and interleukin-1b), pro-inflammatory enzymes (ex; inducible nitric oxide synthase, iNOs), and microRNAs that control tumor progression [2, 3]. Accordingly, developing strategies to reduce inflammation through modulating the NF-KB pathway could be effective in 
preventing/inhibiting the carcinogenesis process. Therefore, evaluating the anti-inflammatory properties of bioactive natural components has received a lot of research coverage [4].

Natural products play an essential role as a source of potent anti-cancer products. It is estimated that almost $60 \%$ of commonly used anti-cancer agents are extracted from natural sources, including plants, micro-organisms, and marine organisms. Clinical trials that apply nutritional supplements as chemoprevention substances are running with promising results [5]. Cruciferous vegetables are rich in several bioactive components, like glucosinolates and their breakdown products that include; Phenethyl isothiocyanate (PEITC), sulforaphane (SFN), and indole-3-carbinol (I3C) and its metabolite 3,3'diindolylmethane (DIM) [6]. Epidemiology studies showed that higher consumption of cruciferous vegetables, such as broccoli, cauliflower, and brussels sprouts, diminishes the risk of cancer, neurological, and cardiovascular diseases. As a nutritional supplement, I3C and DIM have received much attention lately in cancer research due to their promising activity in modulating several oncogenic signaling pathways [7]. More recently, increasing evidence has shown that indole glucosinolates can induce epigenetic alterations, such as histone modifications, DNA methylation, and alternation in non-coding RNAs (like miRNAs), which all contribute to the carcinogenesis process [8,9]. We were interested to further investigate the mechanism through which glucosinolates indoles (I3C and DIM) could modulate the inflammation process accompanied by carcinogenesis. In our study, we used the Ehrlich Ascites Carcinoma (EAC) model, which is a well-established model of tumor biology and is a spontaneous murine mammary adenocarcinoma. EAC is a malignant tumor that can be transplanted and is poorly differentiated. Initially, it started out as a spontaneous breast carcinoma in a mouse model [10]. EAC grows in both solid and ascitic forms. Since these cells lack H-2 histocompatibility antigens, they can multiply and proliferate quickly in almost any mouse host. [11]. A local inflammatory response arises after intraperitoneal inoculation of Ehrlich tumor cells, and the ascitic volume and number of tumor cells gradually increase. Ascites is most likely developed as a result of tumor-induced inflammation, which increases peritoneal vascular permeability; therefore, this model has been widely used in tumor pathogenesis and chemotherapeutic studies $[10,12]$.

The current study aimed to investigate the anti-proliferative and anti-inflammatory effect of indoles (I3C and DIM), through studying the inflammation process controlled by the NF-KB signaling pathway in the Ehrlich Ascites Carcinoma model. This aim was fulfilled by evaluating the modulation effect of indoles on the genes and miRNAs controlling the NF-KB pathway. The results of our study revealed the potent antiinflammatory effect of I3C and DIM

Our results revealed that $\mathrm{I} 3 \mathrm{C}$ and DIM have a potent anti-inflammatory effect, suggesting their involvement as co-treatment with chemotherapeutic drugs would efficiently enhance the anti-tumor effect of the chemotherapeutics

\section{Material And Methods}

\section{Chemicals}


Indole-3-carbinol (I3C), 3,3-diindolylmethane (DIM), and 5-Fluorouracil (5-FU) were all acquired from Sigma-Aldrich (Saint Louis, Mo, USA); they were dissolved in a mixture of dimethylsulfoxide (DMSO) and corn oil and stored at $4^{\circ} \mathrm{C}$ in the dark. Immediately before use, I3C, DIM, and 5-FU were dissolved in physiological saline to the required final concentration used for treatment.

\section{Experimental animals}

Female Swiss albino mice (Fifty mice,20-25g, 8-10 week old) were used in the present study. Mice were housed in stainless steel cages in a controlled environment with a standard laboratory diet and free access to water. Animal Experiment was conducted at the Animal facility unit at the National Research Centre (NRC), Egypt, following the approval of the local animal ethics committee of NRC. The international guidelines for laboratory animal care were strictly applied.

\section{Induction of Ehrlich ascites carcinoma (EAC)}

The parent mouse with Ehrlich ascites carcinoma (EAC) was supplied as a courtesy by the Egyptian National Cancer Institute, Cairo University. The tumor cell line was kept viable in the ascitic form by serial intraperitoneal (i.p.) passages of $2.5 \times 10^{6}$ viable tumor cells in healthy female albino mice as described by previous studies $[13,14]$. Seven days after serial passages of EAC (log phase of cancer cell growth), the EAC cells were collected from the peritoneal cavity and washed twice with phosphate buffer saline (PBS) by centrifugation $10 \mathrm{~min}$ at $1200 \mathrm{rpm}$. After pellet suspension, the total number of tumor cells and the viability of cells were assessed with the trypan blue exclusion test. Cell suspensions with high viability $(\geq 95 \%)$ were used in our experiment .

\section{Experimental design}

Fifty adult female Swiss albino mice were divided into five groups (10 mice each). Forty mice were inoculated with EAC cells by intraperitoneal injection in the peritoneal cavity with $100 \mu \mathrm{l}$ cell suspension $\left(2 \times 10^{6}\right.$ cells) on day zero. The day after, EAC inoculated mice were divided into four groups (10 mice each). A group of ten mice of equitable weight and age, without tumor inoculation, were housed in the same conditions as normal control, only receiving DMSO,

Groups were listed as following: Group I and II were labeled as normal control and EAC control, respectively. Group III (EAC + 5-fluorouracil); mice injected i.p. with EAC cells and then received two doses of 5-fluorouracil (20 mg/kg BW) following the dose used by Yasuda et al., [15]. Group IV (EAC + I3C); mice injected i.p. with EAC cells and orally received I3C (100 mg/kg body weight) daily for ten days. Group V (EAC + DIM); mice injected i.p. with EAC cells and orally received DIM (50 mg/kg BW) daily for 10 days. Doses of I3C and DIM were utilized in our experiment based on earlier findings by others on the potential cytotoxic effect of I3C and DIM on different cancer types [16-20].

Mice were kept under observation for the whole experiment time. Following $24 \mathrm{~h}$ from the last injection (day 11), mice from all groups were sacrificed to collect blood samples from the retro-orbital venous plexus of the eye for biochemical analysis. The ascitic fluids from the peritoneal cavity were completely aspirated to evaluate the tumor volume, the cell growth inhibition percentage, assess the levels of 
different pro-inflammatory markers, and determine the differential expression of miRNAs related to inflammation.

\section{Estimation of packed cell volume and cell growth inhibition}

The collected ascitic fluid from each mouse was centrifuged at $1200 \mathrm{rpm}$ for $5 \mathrm{~min}$, and then the tumor volume was evaluated using a graduated conical centrifuge tube. The viability and non-viability of the cells in the ascitic fluid were assessed by trypan blue assay. The cells that did not stain with the trypan blue dye were considered viable, while cells that accepted the stain were non-viable. All cells were counted using a hemocytometer, cell growth inhibition compared to the positive control group was calculated for each treated group.

\section{Biochemical analysis of the pro-inflammatory biomarkers}

Ascitic fluids from the peritoneal cavity were collected into aseptic tubes, and centrifuged for $20 \mathrm{~min}$ at $3000 \mathrm{rpm}$. Collected cells were homogenized with phosphate buffer saline (PBS) at pH 7.4, and then centrifuged for $20 \mathrm{~min}$ at $3000 \mathrm{rpm}$. The supernatant was collected carefully for evaluation of various biochemical parameters.

\section{Estimation of nitric oxide}

Nitric oxide (NO) of serum and ascitic fluid was evaluated by colorimetric assay using Griess reagent. Griess reagent is used to measure nitrite, the stable end product of NO radicals, that is mainly used as an indicator for nitric oxide production [21].

Estimation of interleukins

Levels of interleukin-6 (IL-6) and interleukin-1b (IL-1b) in serum and ascitic fluid, were evaluated by enzyme-linked immunosorbent assay (ELISA) according to the manufacturer's instructions (Bioneovan Co., Ltd, Beijing, China).

\section{Estimation of nuclear factor kappa B (NF- KB)}

Expression of serum and ascitic fluid of NF- $\mathrm{KB}$ levels were determined using an enzyme-linked immunosorbent assay (ELISA) according to the manufacturer's instructions (Sunlong Biotech Co., Ltd, Zhejiang, China).

\section{Estimation of tumor necrosis factor (TNF-a)}

Expression of serum and ascitic fluid TNF-a levels were evaluated using ELISA according to the manufacturer's instructions (Bioneovan Co., Ltd, Beijing, China).

\section{Total protein quantification}

The protein level in the ascitic fluid was evaluated calorimetrically using a commercial kit (Biuret reagent) according to a method described earlier [22].

RNA extraction and real-time PCR analysis 
Total RNA (including small sequence RNAs) was extracted from ascitic fluid ( $1 \times 10^{6}$ cells) using miRNeasy Kit from Qiagen (Hilden, Germany). The concentration and integrity of the extracted total RNAs were estimated using NanoDrop1000 (Thermo Fisher Scientific GmbH, Dreieich, Germany) at A260/A280 $\mathrm{nm}$. Complementary DNA (cDNA) was synthesized using Qiagen miScript reverse transcriptase with a final volume of $20 \mu \mathrm{l}$ at the following conditions; $37^{\circ} \mathrm{C}$ for one hour, then inactivation step at $95^{\circ} \mathrm{C}$ for 5 min to terminate the reaction. RT-PCR was performed using SYBR Green under certain cycling circumstances; $95^{\circ} \mathrm{C}$ for $15 \mathrm{~min}$, then $35 \mathrm{cycles}$ at $94^{\circ} \mathrm{C}$ for $15 \mathrm{sec}, 55^{\circ} \mathrm{C}$ for $30 \mathrm{sec}$, and $70^{\circ} \mathrm{C}$ for $30 \mathrm{sec}$. A dissociation curve was performed at the end of each PCR run to verify amplification specificity. Relative expression for each miRNA was estimated with the $2^{-\Delta \Delta C t}$ calculation method, where samples were normalized to the internal control RNU6. Primers used for RT-PCR are miScript Primer Assays from Qiagen collections as following;

- miR-31_1 miScript Primer Assay (Cat\# MS00003290).

- miR-21_2miScript Primer Assay (Cat\# MS00009079).

- RNU6-2_11 miScript Primer Assay (Cat \#MS00033740).

\section{Statistical Analysis}

Statistical analysis was conucted using GraphPad-Prism ${ }^{\circledR}$ Version 5 for windows. The mean and standard deviation (SD) is used to express all results, with $95 \%$ confidence intervals. One-way ANOVA was used for statistical analysis with normal distribution followed by Post-hoc Tukey HSD test for comparisons between different groups. Differences with $p<0.05$ were considered significant as following; \#) illustrate significance comparing to control, a) significance comparing to EAC control, b) significance comparing to $\mathrm{EAC}+5-\mathrm{FU}$, and $\mathrm{c}$ ) significance comparing to $\mathrm{EAC}+\mathrm{I3C}$.

\section{Results}

\section{Evaluation of the packed cell volume and cell growth inhibition}

To evaluate the anti-tumor effect of $\mathrm{I} 3 \mathrm{C}$ and DIM, changes in the tumor volume and cell viability of treated groups were detected (Table 1). Mice inoculated with EAC and treated with I3C or DIM showed a significant reduction in the volume of ascetic fluid compared to EAC control mice $(P<0.05)$. In addition, I3C and DIM showed efficiency in reducing cell viability, reaching $68 \%$ and $47 \%$ inhibition, respectively, in comparison to the EAC control group. The anti-tumor effect of 5-Fu, on the other hand, was more significant regarding reduction in tumor volume or cell growth inhibition (31\%), as shown in Table 1.

\section{Table (1): Packed cell volume and cell growth inhibition in the different studied groups}




\begin{tabular}{|c|c|c|c|}
\hline $\begin{array}{l}\text { Parameters } \\
\text { Groups }\end{array}$ & Packed cell volume (ml) & $\begin{array}{l}\text { Viable cell count } \\
\left(10^{\wedge} 6 \text { cells } / \mathrm{ml}\right)\end{array}$ & Cell Growth inhibition (\%) \\
\hline Control EAC & $9.55 \pm 0.8$ & $96.4 \pm 11.2$ & - \\
\hline $\mathrm{EAC}+5-\mathrm{FU}$ & $2.9^{a} \pm 0.6$ & $30.1 \pm 7.01^{\mathrm{a}}$ & $31 \%$ a \\
\hline$E A C+13 C$ & $5.9^{a, b} \pm 0.9$ & $65.6 \pm 8.5 \mathrm{a}, \mathrm{b}$ & $68 \% a, b$ \\
\hline$E A C+D I M$ & $3.5^{\mathrm{a}, \mathrm{c}} \pm 0.5$ & $45.7 \pm 6.9^{a, b, c}$ & $47 \%$ a, b,c \\
\hline
\end{tabular}

\section{Evaluation Of Pro-inflammatory Biomarkers In Serum And Eac Samples}

The levels of serum inflammatory biomarkers (nitrite, TNF- a, NF-KB, IL-6, and IL-1b) in the various study groups are summarised in Table (2). Statistical analysis showed a significant increase in the serum levels of all inflammatory biomarkers in all groups inoculated with EAC compared to the normal control group. Treatment with 5-FU showed the highest significance increase in the serum levels of nitrite, TNF-a, NF-KB, IL-6, and IL-1b compared to other groups (Table 2). Treating EAC-bearing mice with I3C or DIM was able to significantly reduce the elevation in the levels of these inflammatory biomarkers. Mice treated with DIM showed the mot reduction in comparison to all other EAC-bearing groups, suggesting the powerful effect of DIM as an anti-inflammatory.

Table (2): Serum inflammatory biomarkers in different studied groups

\begin{tabular}{|c|c|c|c|c|c|}
\hline $\begin{array}{l}\text { Parameters } \\
\text { Groups }\end{array}$ & $\begin{array}{l}\text { Nitrite } \\
(\mu \mathrm{mol} / \mathrm{l})\end{array}$ & TNF- $\mathrm{a}(\mathrm{pg} / \mathrm{ml})$ & NF-KB (pg/ml) & $\begin{array}{l}\text { IL-6 } \\
\text { (pg/ml) }\end{array}$ & $\begin{array}{l}\text { IL-1b } \\
(\mathrm{pg} / \mathrm{ml})\end{array}$ \\
\hline $\begin{array}{l}\text { Normal } \\
\text { Control }\end{array}$ & $15.1 \pm 0.4$ & $78.9 \pm 2.2$ & $96.4 \pm 4.8$ & $41.3 \pm 2.9$ & $14.74 \pm 4.1$ \\
\hline EAC & $41.9^{\#} \pm 6.08$ & $260.5^{\#_{ \pm}} 5.5$ & $499.1^{\# \pm 3.8}$ & $105.2 \# \pm 3.9$ & $37.8^{\#_{ \pm}} 1.5$ \\
\hline $\mathrm{EAC}+5-\mathrm{FU}$ & $\begin{array}{l}50.9^{\#, a} \pm \\
8.8^{-1}\end{array}$ & $369.8^{\#, a} \pm 6.3$ & $601.4^{\#, a} \pm 9.5$ & $\begin{array}{l}157.6^{\#, a} \pm \\
4.9^{*}\end{array}$ & $75.9^{\#, a} \pm 2$ \\
\hline$E A C+13 C$ & $\begin{array}{l}34.1^{\#, a, b} \pm \\
6.0\end{array}$ & $306.9^{\#, a, b} \pm 7.1$ & $446.1^{\#, a, b} \pm 4$ & $101.2^{\#, b} \pm 4.2$ & $35.3^{\#, b} \pm 1.4$ \\
\hline$E A C+D I M$ & $22.9^{\#, a, b, c} \pm$ & $\begin{array}{l}224.5^{\#, a, b, c} \pm \\
4.3\end{array}$ & $\begin{array}{l}352.7^{\#, a, b, c} \pm \\
6.6\end{array}$ & $\begin{array}{l}88.2^{\#, a, b, c} \pm \\
3.9^{-1}\end{array}$ & $\begin{array}{l}22.8^{\#, a, b, c} \pm \\
3.4\end{array}$ \\
\hline
\end{tabular}

\#: significance comparing to normal control, a. significance comparing to EAC control, b: significance comparing to $\mathrm{EAC}+5-\mathrm{FU}$, and ${ }^{\mathrm{c}}$ : significance comparing to $\mathrm{EAC}+\mathrm{I3C}$. 
Concomitant with the serum results, EAC homogenate samples showed a significant increase in the inflammatory biomarkers in mice bearing EAC and treated with 5-FU in comparison to the EAC control group. On the other hand, treatment with I3C showed a significant decrease in TNF-a, NF-KB, IL-6, and IL$1 \mathrm{~b}$ compared to both EAC control group and EAC group treated with 5-FU. Administration of DIM showed the most significant decrease in TNF- $a, N F-K B, I L-6$, and IL-1b compared to all other EAC-bearing groups either treated with 5-FU, I3C, or non-treated (Fig. 1).

\section{The differential expression of miR-21 and miR-31 in EAC samples}

To estimate whether the potential anti-inflammation effect of I3C and DIM is modulated by differential expression of two miRNAs that are documented to be involved in the inflammation process, we evaluated the relative expression of miR-21 and miR-31 in EAC homogenate samples from all groups inoculated with EAC and treated with 5-FU, I3C, or DIM in comparison with EAC control group.

In parallel with our previous data on the levels of inflammatory biomarkers, Our results revealed that the expression of miR-31and miR-21 was markedly increased in mice inoculated with EAC and treated with 5FU compared to the EAC control group. However, this over-expression was significantly decreased in mice treated with I3C or DIM compared to both EAC control group and EAC + 5-FU group. Worth mentioning, administration of DIM showed the utmost significant reduction in the expression of both miR-31and miR21 compared to both EAC control group and mice bearing EAC and treated with 5-FU (Fig. 2). Moreover, a significant reduction in miR-21 in DIM treated group comparing to $13 \mathrm{C}$ treated group was detected.

\section{Correlation between levels of NF-kB and expression of miR-31 and mi-21}

We were interested in evaluating whether the change in the expression level of the miRNAs target gene NF-KB shows a positive or negative correlation with that of the miRNAs themselves (miR-31 and miR-21). Therefore, a pairwise Pearson's correlation was performed to evaluate the correlation between expression of NF-KB and miR-31 and miR-21 in all mice inoculated with EAC and treated with 5-FU, IC, DIM, or served as control. Applying this approach, we could detect a statistically significant positive correlation of NF-KB - miR-31 and NF-KB-miR-21 pairs with a mean Pearson's correlation coefficient of 0.858 and 0.655 , respectively (Fig. 3).

\section{Discussion}

There is a strong correlation between inflammation and cancerous lesions development at different anatomic sites. Several studies reported that inflammatory signaling pathways appear to induce and facilitate carcinogenesis. Inflammatory biomarkers as cytokines, inducible nitric oxide synthase (iNOS), and NF-kB are upregulated during chronic inflammation. These processes work together to create a favorable microenvironment for malignant cells to proliferate aggressively. As a result, inflammation can provide the required mutations and the proper environment for tumor development [23]. NF-KB signaling is the master regulator for most inflammatory signaling cascades, including interleukin-1 (IL-1), IL-6, IL-8, TNF-a, and transcription of several inflammatory mediators [24]. This can be observed in our study, where 
all mice inoculated with EAC significantly showed a marked increase in levels of nitric oxide, the inflammatory cytokines (TNF-a, IL-1b, and IL-6), and NF-KB in serum and ascetic fluid as compared to normal control group.

There are numerous studies on potential anti-inflammatory agents that are designed to reduce or prevent inflammation, in addition to their efficiency as anti-proliferative agents, making them promising candidates for cancer prevention and/or therapy. Natural products have long provided front-line pharmacotherapy for many chronic diseases. They are essential sources of biologically active compounds and are considered a promising avenue for discovering new drugs due to easy access and relatively low cost. Herbal remedies are used to treat acute and chronic diseases, inhibit the progression of many chronic types of cancers, attenuate inflammation, and modulate cell signaling pathways [2527].

The dietary components indole-3-carbinol (I3C) and its metabolite 3,3'-diindolylmethane (DIM), which are derived from naturally occurring glucosinolates in the Cruciferae family, have received a lot of attention regarding their preventive and/or therapeutic effect on various types of cancer, especially hormonaldependent cancers such as breast and cervical cancer $[8,28]$.

In the present study, the anti-proliferative effect of I3C and DIM were observed by the profound inhibition of packed cell volume and cell viability compared to EAC control group. The effectiveness of I3C and DIM in targeting multiple signaling pathways regulating apoptosis, DNA repair, hormonal homeostasis, and cell cycle is largely responsible for their anti-tumor effects. I3C and DIM could trigger cell cycle arrest in the $\mathrm{G} 1$ phase, preventing cells from moving from the $\mathrm{G} 1$ to the $S$ phase. In a recent study, we discovered that this cell cycle effect was mediated by a change in the expression of a panel of miRNAs that regulate the $\mathrm{G} 1 / \mathrm{S}$ process of the cell cycle [8].

According to the present results, the anti-proliferative effect of 5-Fu was more prominent than that detected by I3C or DIM (Table 1). 5-Fluorouracil is a fluorinated pyrimidine with intense anti-cancer activity based on its ability to interfere with nucleotide metabolism, as well as RNA and DNA synthesis, leading to the suppression of DNA replication [28]. The most restrictions of 5-FU are its chemo-resistance, rapid elimination from the body, the need to use high doses to achieve a significant effect, and the induction of severe inflammatory responses [29]. Many inflammatory mediators and cytokines play crucial role in the control and modulation of patients' responses to 5-FU therapy. Several studies reported that the toxicity induced by $5-\mathrm{FU}$ was accompanied by elevated expression of cytokines (IL-1 $\beta$, IL-6, TNFa), EGFR, and the level COX-2 stimulated by NF-KB [30,31]. Chang et al. reported that 5-FU causes the release of reactive oxygen species (ROS) and pro-inflammatory cytokines, such as IL-1 $\beta$, IL-6, and TNF-a, resulting in the activation of inflammatory response [32]. These results agree with our study, where we observed that the potent anti-tumor effect detected by 5 -FU was in parallel with a concomitant increase in the levels of the inflammatory biomarkers NO, TNF- $a$, IL-6, IL-1b, and NF-KB in both serum and ascetic fluid. Stimulation of systemic inflammation by chemotherapies could be attributed to tissue damage and cell apoptosis as a result of the cytotoxicity effect, and also the elevation of reactive oxygen species 
through inducing the myeloperoxidase enzymes (MPO), a neutrophil marker [33-35]. Alternative therapeutics that can impair the side effects of 5-FU, without affecting treatment efficiency are urgently needed.

According to our study, administration of I3C or DIM was able to reduce the systemic inflammation state detected in EAC bearing mice. A significant reduction in the levels of inflammatory markers in serum and ascetic fluids was reported, especially with EAC bearing mice treated with DIM. The effectiveness of DIM over I3C could be linked to the instability and low molecule half-life of $I 3 \mathrm{C}$ and its rapid clearance by the kidneys, as well as its rapid inactivation due to metabolic enzymes, low molecular weight, low water solubility, gastrointestinal tract instability.

On the other hand, DIM has a greater stability compared to I3C after oral ingestion. As a result, I3C must be taken at a much higher amount and can undergo unpredictable chemical reactions in the stomach environment $[36,37]$. Therefore, DIM is thought to be largely responsible for the detected chemopreventive/therapeutic effects of indoles $[8,38]$. The potent anti-inflammatory effect of DIM could be attributed to its ability to attenuate the DNA-binding activity of NF-KB by blocking the phosphorylation of IKB. In the study by Kim et al. [39], The DIM inhibitory effect on NF-KB signaling contributed to the significant reduction in the expression of COX-2 and iNOS in DIM-treated BV microglia. This study suggested that the inhibition of ІкB phosphorylation is the mechanism through which DIM could attenuate microglial hyperactivity and eventually protect against inflammation state that mediate neurodegeneration [39].

Among several dysregulated signaling pathways, NF-KB is the leading cell signaling pathway known to malfunction in numerous malignancies and the most crucial pathway involved in initiating and developing inflammatory responses [40]. The inactivated form of NF-KB is present in the cytoplasm binding with inhibitory protein ( $\mathrm{I} \mathrm{K} B$ ) family members. In case of inflammation, IKB kinase phosphorylates IKB, which induces its degradation, and eventually the liberation of NF-KB [41]. As a result, NF-KB reaches the nucleus and stimulates the expression of genes involved in inflammation. IL-1, IL-6, TNF-, monocyte chemoattractant protein-1 (MCP-1), C-X-C motif chemokine ligand-1, and - 10 (CXCL1 and CXCL10) are among the pro-inflammatory cytokines or chemokines encoded by the majority of these genes. [40,42]. Several transcription factors, including NF-KB, have binding sites in the promoter region of the iNOS gene. Activation of NF-KB will directly enhance the expression of iNOS [43]. Therefore, NF-KB is considered the primary regulator of the inflammation signaling pathway.

MiRNAs are vital transcriptional regulators implicated in the regulation of several genes. Studies have reported that miRNAs are involved in the progression of different malignancies and are considered significant factors in cancer pathogenesis [44-46]. Furthermore, the initiation of the cancer-induced inflammatory processes is also controlled by miRNAs that could regulate the NF-KB signaling pathway [47]. miRNAs are vital transcriptional regulators implicated in the regulation of NF-KB signaling pathway by negatively or positively regulating genes involved in cancer initiation, progression, metastasis, and 
also drug resistance. As a result, miRNAs have been implemented as molecular therapeutic targets and markers for cancer diagnosis and prognosis [48].

Controlling the expression of miRNA is a powerful incentive for tumor therapy. miR-21 and miR-31 are oncogenic miRNAs that regulate various downstream effectors associated with cancer and are reported to be elevated in many inflammation-associated diseases [48]. miR-21 is one of the most consistently upregulated oncomiRs in human cancers and is strongly associated with tumor progression, it is commonly utilized as a diagnostic, prognostic, and metastasis biomarker for various types of cancer and also as a potential therapeutic target [49]. miR-21 expression is regulated by NF-KB by binding to its element site in the NF-kB promoter [50]. miR-31 is also positively correlated to inflammatory diseaseassociated neoplastic transformation. MiR-31 mediates inflammatory signaling and is directly regulated by the activity of NF-KB [51]. Yan et al., [52] reported that NF-KB could significantly induce miR-31 and its target, protein phosphatase 6 (ppp6c), the critical factor for epidermal hyperplasia. Moreover, Upregulated miR-31 can target and suppress STK40, a known negative regulator of NF-KB, causing an activation of the NF-KB pathway and eventually enhancing the inflammatory response [53,54]. This correlation between NF-KB activation and the upregulation of miR-31 and miR-21 expression was detected in our present study in all mice inoculated with EAC. The levels of miR-31 and-21 were significantly up regulated whenever the NF-KB level and the inflammation state were significantly high. On the other hand, repression of NF-KB level and alleviation of inflammation was accompanied by a reduction in the level of miR-31 and miR-21. This correlation was statistically confirmed by Pearson's correlation coefficient, where differential expression of miR-31 and miR-21 was positively correlated with the expression of NFkB.

\section{Conclusion}

Treatment of Ehrlich ascites tumor with indole glucosinolates (I3C or DIM) were able to reduce the proliferation of tumor cells, attenuate the increase in inflammatory cytokines, suppresses the activation of NF-KB, and inhibits the expression of interleukins associated with the NF-KB pathway, consequently reduce the inflammation state. This study also revealed that I3C and DIM exert their anti-inflammatory effect via attenuating the abnormal elevation of the miRNAs inflammatory mediators miR-31 and miR-21. These results suggest that the administration of indole glucosinolates (I3C or DIM) as co-treatment with chemotherapeutic drugs would efficiently enhance the anti-tumor effect of the chemotherapeutics by suppressing tumor cell proliferation and, most importantly, attenuate the inflammation state that is evolved from tumor cell proliferation and/or chemotherapeutic administration.

\section{Declarations}

\section{Funding}

This research was partially supported by the National Research Centre, Cairo, Egypt (Grant No\# 11010332). 


\section{Compliance with ethical standards}

\section{Conflict of interest}

All authors declare no confict of interest.

\section{Ethical approval}

All animal procedures of the current protocol were approved by the animal ethics committee of the National Research Centre, Cairo, Egypt.

\section{Author contribution}

El-Daly S. M., Fathy S. A., Mohamed R. M., and El-Khayat Z. developed the idea and planned the work.

Salem A. Z. Medhat D., and El-Daly S. M. performed the required experiments.

Medhat D., El-Daly S. M., and Salem A. Z. wrote the manuscript in consultation with El-Khayat Z.

Fathy S. A., Mohamed R. M., participated in drafting the article and reviewing the manuscript.

\section{Consent to Participate}

We verify a significant contribution from all the authors listed on the title page, and that they are fully aware of the manuscript's content, verify that the data and its interpretation are valid and legitimate.

\section{Consent to Publish}

All authors mutually agree to forward this manuscript for submission. All authors discussed the results and contributed to the final form of the manuscript. We affirm that the submitted manuscript has not been previously published in any language anywhere and is not submitted for publication elsewhere.

\section{References}

1. Bray F, Ferlay J, Soerjomataram I et al (2018) Global cancer statistics 2018: GLOBOCAN estimates of incidence and mortality worldwide for 36 cancers in 185 countries. CA Cancer J Clin. https://doi.org/10.3322/caac.21492

2. Didonato JA, Mercurio F, Karin M (2012) NF-KB and the link between inflammation and cancer. Immunol Rev. https://doi.org/10.1111/j.1600-065X.2012.01099.x

3. Wu J, Ding J, Yang J et al (2018) MicroRNA Roles in the Nuclear Factor Kappa B Signaling Pathway in Cancer. Front Immunol 9:546

4. Maione F, Russo R, Khan H, Mascolo N (2016) Medicinal plants with anti-inflammatory activities. Nat. Prod. Res 
5. Rayan A, Raiyn J, Falah M (2017) Nature is the best source of anticancer drugs: Indexing natural products for their anticancer bioactivity. PLoS One. https://doi.org/10.1371/journal.pone.0187925

6. Agerbirk N, De Vos M, Kim JH, Jander G (2009) Indole glucosinolate breakdown and its biological effects. Phytochem. Rev

7. Fuentes F, Paredes-Gonzalez X, Kong ANT (2015) Dietary Glucosinolates Sulforaphane, Phenethyl Isothiocyanate, Indole-3-Carbinol/3,3'-Diindolylmethane: Antioxidative Stress/Inflammation, Nrf2, Epigenetics/Epigenomics and In Vivo Cancer Chemopreventive Efficacy. Curr. Pharmacol. Reports

8. El-Daly SM, Gamal-Eldeen AM, Gouhar SA et al (2020) Modulatory Effect of Indoles on the Expression of miRNAs Regulating G1/S Cell Cycle Phase in Breast Cancer Cells. Appl Biochem Biotechnol 192:1208-1223. https://doi.org/10.1007/s12010-020-03378-8

9. Montgomery M, Srinivasan A (2019) Epigenetic Gene Regulation by Dietary Compounds in Cancer Prevention. Adv. Nutr

10. Ozaslan M, Karagoz I, Kilic I, Guldur M (2013) Ehrlich ascites carcinoma. African J Biotechnol. https://doi.org/10.5897/AJBx10.017

11. Chen L, Watkins JF (1970) Evidence against the presence of $\mathrm{H} 2$ histocompatibility antigens in ehrlich ascites tumour cells. Nature. https://doi.org/10.1038/225734a0

12. Mishra S, Tamta AK, Sarikhani M et al (2018) Subcutaneous Ehrlich Ascites Carcinoma mice model for studying cancer-induced cardiomyopathy. Sci Rep. https://doi.org/10.1038/s41598-018-23669-9

13. Medhat D, Hussein J, El-Naggar ME et al (2017) Effect of Au-dextran NPs as anti-tumor agent against EAC and solid tumor in mice by biochemical evaluations and histopathological investigations. Biomed Pharmacother 91:. https://doi.org/10.1016/j.biopha.2017.05.043

14. Tannock IF (1969) A Comparison of Cell Proliferation Parameters in Solid and Ascites Ehrlich Tumors. Cancer Res

15. Yasuda M, Kato S, Yamanaka N et al (2013) 5-HT3 receptor antagonists ameliorate 5fluorouracilinduced intestinal mucositis by suppression of apoptosis in murine intestinal crypt cells. Br J Pharmacol 168:1388-1400. https://doi.org/10.1111/bph.12019

16. Wilker C, Johnson L, Safe S (1996) Effects of developmental exposure to indole-3-carbinol or 2,3,7,8tetrachlorodibenzo-p-dioxin on reproductive potential of male rat offspring. Toxicol Appl Pharmacol. https://doi.org/10.1006/taap.1996.0261

17. Grubbs CJ, Steele VE, Casebolt T et al (1995) Chemoprevention of chemically-induced mammary carcinogenesis by indole-3-carbinol. Anticancer Res

18. Gao N, Cheng S, Budhraja A et al (2012) 3, 3'-Diindolylmethane exhibits antileukemic activity in vitro and in vivo through a Akt-dependent process. PLoS One

19. Reed GA, Sunega JM, Sullivan DK et al (2008) Single-dose pharmacokinetics and tolerability of absorption-enhanced 3,3'-diindolylmethane in healthy subjects. Cancer Epidemiol Biomarkers Prev. https://doi.org/10.1158/1055-9965.EPI-08-0520 
20. Howells LM, Moiseeva EP, Neal CP et al (2007) Predicting the physiological relevance of in vitro cancer preventive activities of phytochemicals. Acta Pharmacol. Sin

21. Moshage $H$, Kok B, Huizenga JR, Jansen PLM (1995) Nitrite and nitrate determinations in plasma: $A$ critical evaluation. Clin Chem 41:892-896. https://doi.org/10.1093/clinchem/41.6.892

22. Passing H, Bablok W (2009) A New Biometrical Procedure for Testing the Equality of Measurements from Two Different Analytical Methods. Application of linear regression procedures for method comparison studies in Clinical Chemistry, Part I. Clin Chem Lab Med 21:709-720. https://doi.org/10.1515/cclm.1983.21.11.709

23. Greten FR, Grivennikov SI (2019) Inflammation and Cancer: Triggers, Mechanisms, and Consequences. Immunity

24. Ben-Neriah Y, Karin M (2011) Inflammation meets cancer, with NF-kB as the matchmaker. Nat. Immunol

25. Andrijauskaite K, Wargovich MJ (2020) Role of natural products in breast cancer related symptomology: Targeting chronic inflammation. Semin. Cancer Biol

26. QIN J, WANG W, ZHANG R (2017) Novel natural product therapeutics targeting both inflammation and cancer. Chin J Nat Med. https://doi.org/10.1016/S1875-5364(17)30062-6

27. Esteve M (2020) Mechanisms Underlying Biological Effects of Cruciferous Glucosinolate-Derived Isothiocyanates/Indoles: A Focus on Metabolic Syndrome. Front. Nutr

28. An Q, Robins P, Lindahl T, Barnes DE (2007) 5-Fluorouracil incorporated into DNA is excised by the Smug1 DNA glycosylase to reduce drug cytotoxicity. Cancer Res. https://doi.org/10.1158/00085472.CAN-06-2960

29. Zhang N, Yin Y, Xu SJ, Chen WS (2008) 5-Fluorouracil: Mechanisms of resistance and reversal strategies. Molecules

30. Groves TR, Farris R, Anderson JE et al (2017) 5-Fluorouracil chemotherapy upregulates cytokines and alters hippocampal dendritic complexity in aged mice. Behav Brain Res. https://doi.org/10.1016/j.bbr.2016.08.039

31. Janelsins MC, Mustian KM, Palesh OG et al (2012) Differential expression of cytokines in breast cancer patients receiving different chemotherapies: Implications for cognitive impairment research. Support Care Cancer. https://doi.org/10.1007/s00520-011-1158-0

32. Chang CT, Ho TY, Lin H et al (2012) 5-fluorouracil induced intestinal mucositis via nuclear factor-KB activation by transcriptomic analysis and in vivo bioluminescence imaging. PLoS One 7:1-8. https://doi.org/10.1371/journal.pone.0031808

33. De Sousa Fideles L, De Miranda JAL, Da Silva Martins C et al (2020) Role of rutin in 5-fluorouracilinduced intestinal mucositis: Prevention of histological damage and reduction of inflammation and oxidative stress. Molecules. https://doi.org/10.3390/molecules25122786

34. Justino PFC, Melo LFM, Nogueira AF et al (2014) Treatment with Saccharomyces boulardii reduces the inflammation and dysfunction of the gastrointestinal tract in 5-fluorouracil-induced intestinal mucositis in mice. Br J Nutr. https://doi.org/10.1017/S0007114513004248 
35. Wang L, Chen Q, Qi H et al (2016) Doxorubicin-induced systemic inflammation is driven by upregulation of toll-like receptor TLR4 and endotoxin leakage. Cancer Res. https://doi.org/10.1158/0008-5472.CAN-15-3034

36. Reed GA, Arneson DW, Putnam WC et al (2006) Single-dose and multiple-dose administration of indole-3-carbinol to women: Pharmacokinetics based on 3,3'-diindolylmethane. Cancer Epidemiol Biomarkers Prev 15:2477-2481. https://doi.org/10.1158/1055-9965.EPI-06-0396

37. Bradlow HL, Zeligs MA (2010) Diindolylmethane (DIM) spontaneously forms from indole-3-carbinol (I3C) during cell culture experiments. In Vivo (Brooklyn)

38. Biersack B (2020) 3,3'-Diindolylmethane and its derivatives: nature-inspired strategies tackling drug resistant tumors by regulation of signal transduction, transcription factors and microRNAs. Cancer Drug Resist. https://doi.org/10.20517/cdr.2020.53

39. Kim HW, Kim J, Kim J et al (2014) 3,3'-Diindolylmethane Inhibits Lipopolysaccharide-Induced Microglial Hyperactivation and Attenuates Brain Inflammation. Toxicol Sci. https://doi.org/10.1093/toxsci/kft240

40. Xiao C, Ghosh S (2005) NF-kB, an evolutionarily conserved mediator of immune and inflammatory responses. In: Advances in Experimental Medicine and Biology

41. Yamamoto Y, Gaynor RB (2004) IkB kinases: Key regulators of the NF-kB pathway. Trends Biochem. Sci

42. Li Q, Verma IM (2002) NF-kappaB regulation in the immune system. Nat Rev Immunol

43. Natarajan K, Abraham P, Kota R, Isaac B (2018) NF-KB-iNOS-COX2-TNF a inflammatory signaling pathway plays an important role in methotrexate induced small intestinal injury in rats. Food Chem Toxicol. https://doi.org/10.1016/j.fct.2018.06.040

44. El-Daly SM, Abba ML, Patil N, Allgayer H (2016) MiRs-134 and-370 function as tumor suppressors in colorectal cancer by independently suppressing EGFR and PI3K signalling. Sci Rep. https://doi.org/10.1038/srep24720

45. Hannafon BN, Ding WQ (2019) Functional Role of miRNAs in the Progression of Breast Ductal Carcinoma in Situ. Am. J. Pathol

46. El-Daly SM, Bayraktar R, Anfossi S, Calin GA (2020) The Interplay between MicroRNAs and the Components of the Tumor Microenvironment in B-Cell Malignancies. Int. J. Mol. Sci

47. El-Daly SM, Omara EA, Hussein J et al (2019) Differential expression of miRNAs regulating NF-KB and STAT3 crosstalk during colitis-associated tumorigenesis. Mol Cell Probes. https://doi.org/10.1016/j.mcp.2019.101442

48. El-Daly SM, Morsy SM, Medhat D et al (2019) The diagnostic efficacy of circulating miRNAs in monitoring the early development of colitis-induced colorectal cancer. J Cell Biochem. https://doi.org/10.1002/jcb.28925

49. Wang H, Tan Z, Hu H et al (2019) MicroRNA-21 promotes breast cancer proliferation and metastasis by targeting LZTFL1. BMC Cancer. https://doi.org/10.1186/s12885-019-5951-3 
50. Yang Z, Fang S, Di Y et al (2015) Modulation of NF-KB/miR-21/PTEN pathway sensitizes non-small cell lung cancer to cisplatin. PLoS One. https://doi.org/10.1371/journal.pone.0121547

51. Shi J, Ma X, Su Y et al (2018) MiR-31 Mediates Inflammatory Signaling to Promote ReEpithelialization during Skin Wound Healing. J Invest Dermatol. https://doi.org/10.1016/j.jid.2018.03.1521

52. Yan S, Xu Z, Lou F et al (2015) NF-kB-induced microRNA-31 promotes epidermal hyperplasia by repressing protein phosphatase 6 in psoriasis. Nat Commun. https://doi.org/10.1038/ncomms8652

53. Alder $\mathrm{H}$, Taccioli $\mathrm{C}$, Jiang $\mathrm{Y}$ et al (2012) Dysregulation of miR-31 and miR-21 induced by zinc deficiency promotes esophageal cancer. 33:1736-1744. https://doi.org/10.1093/carcin/bgs204

54. Yu T, Ma P, Wu D et al (2018) Functions and mechanisms of microRNA-31 in human cancers. Biomed Pharmacother 108:1162-1169. https://doi.org/10.1016/j.biopha.2018.09.132

\section{Figures}
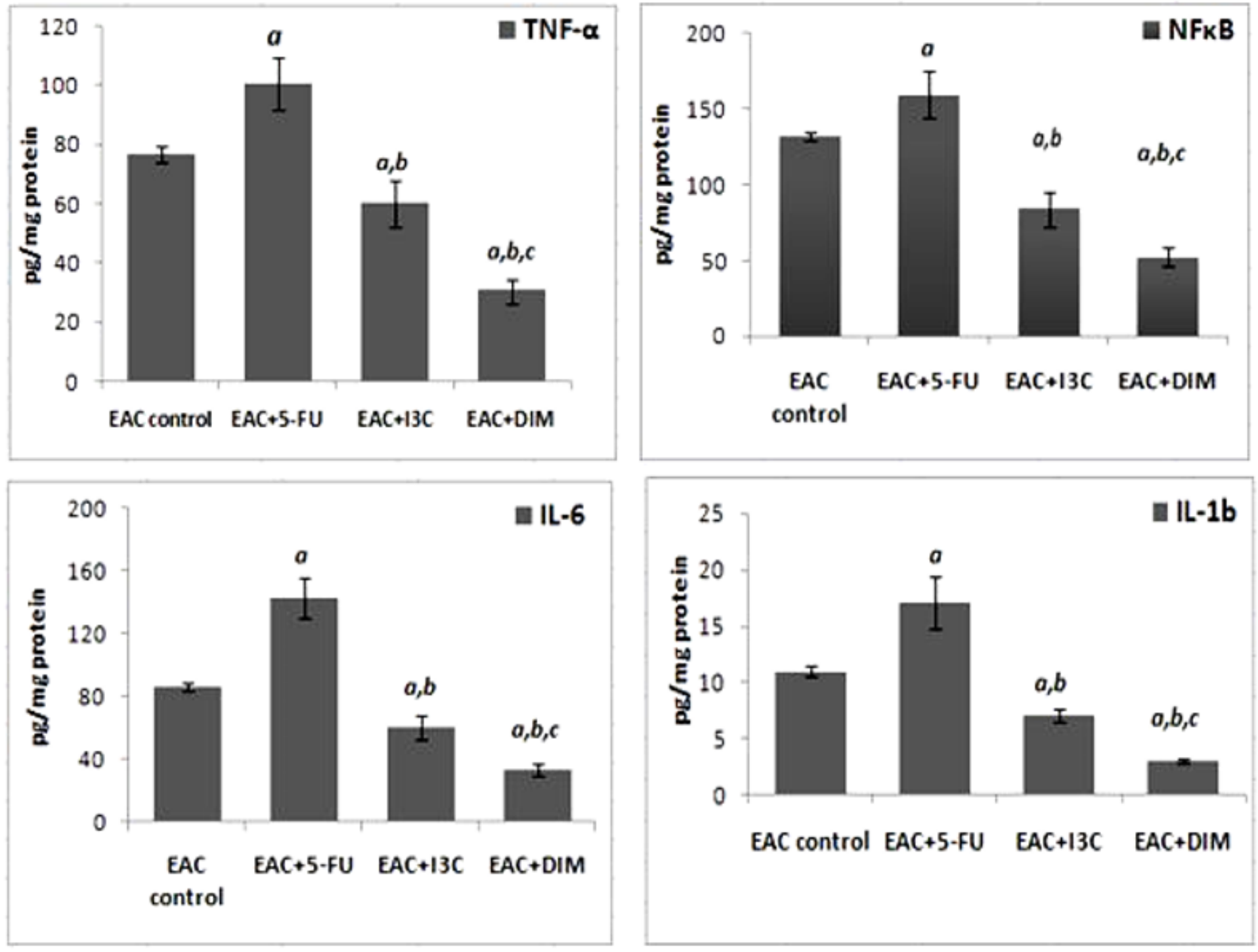
Figure 1

Levels of EAC pro-inflammatory biomarkers in different studied groups a: significance comparing to EAC control, b: significance comparing to EAC + 5-FU, and c: significance comparing to EAC + I3C.
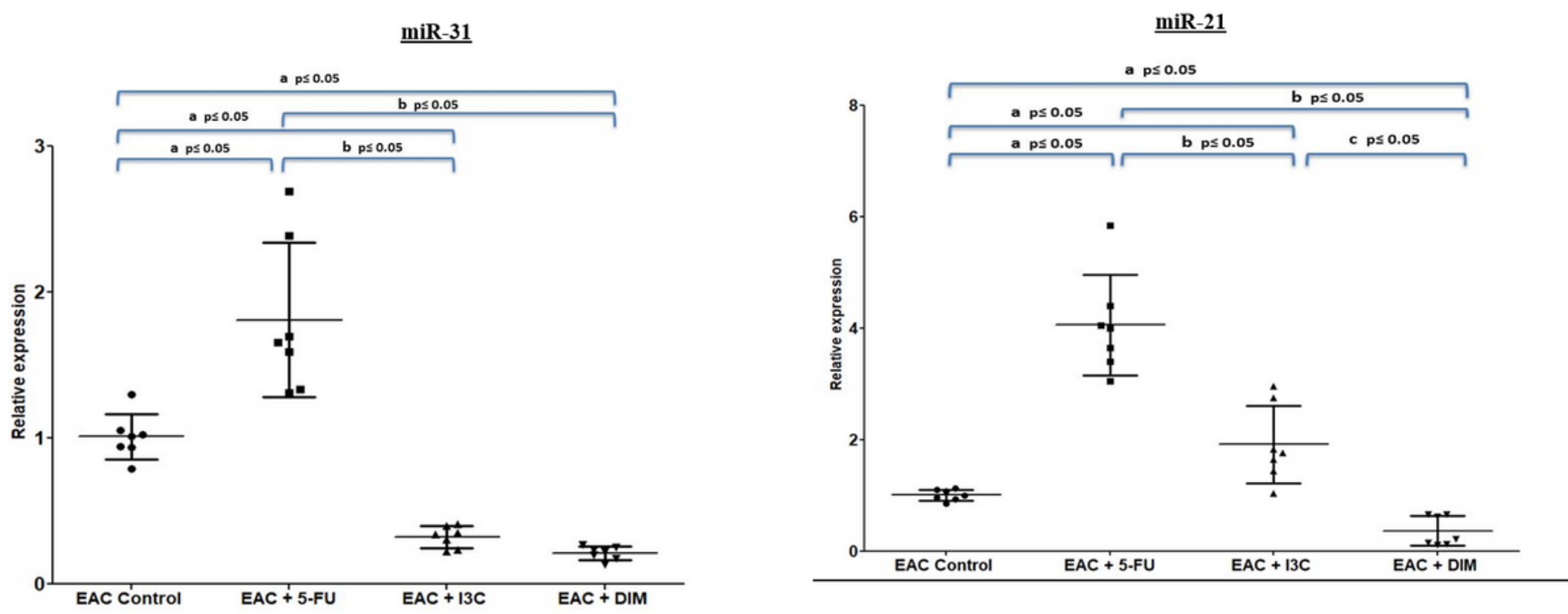

Figure 2

The relative expression of the miRNA-31 and miRNA-21 in EAC- bearing mice. Expression levels of miRNAs are normalized to RNU6. Statistically significant differences between groups were evaluated using ANOVA and post-hoc Tukey HSD test for comparisons. a: significance comparing to EAC control, b: significance comparing to EAC + 5-FU, and c: significance comparing to EAC + I3C. 

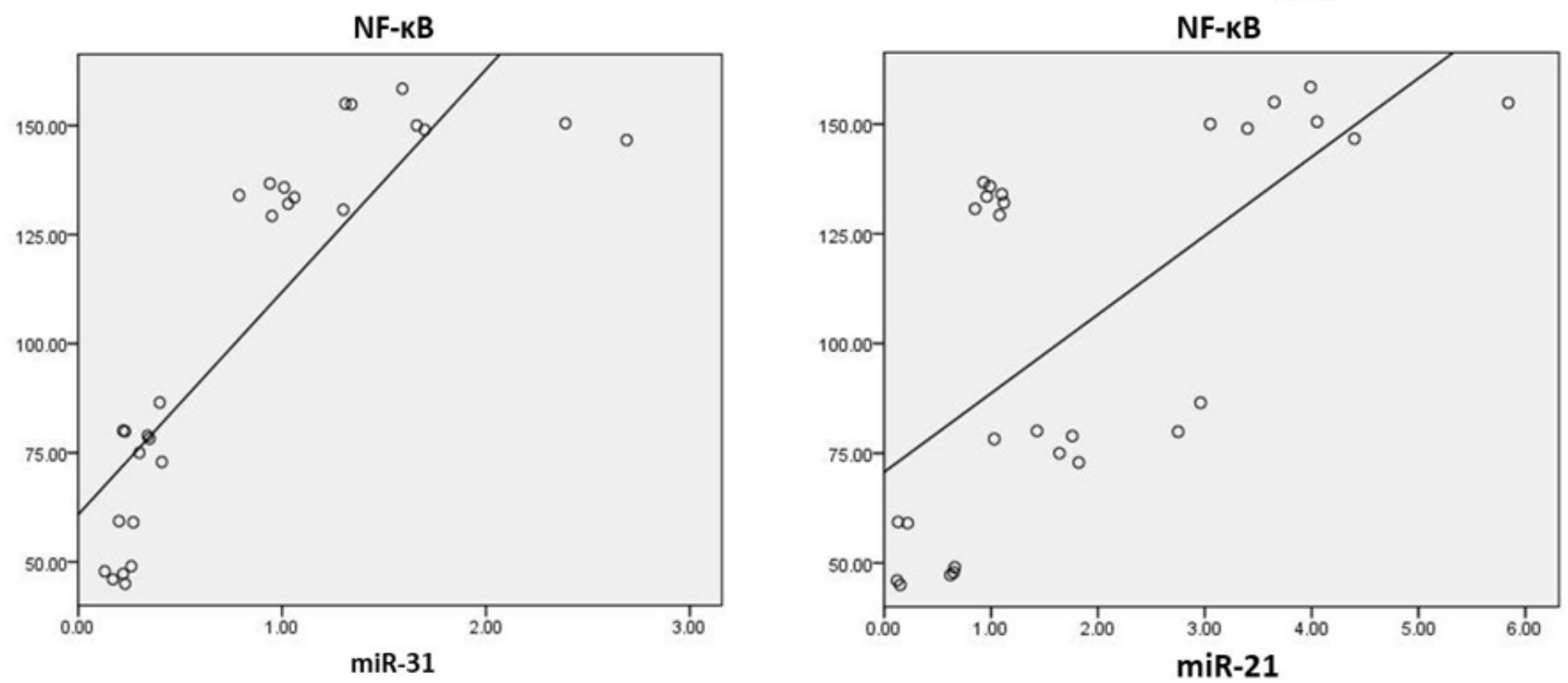

\section{Correlations}

\begin{tabular}{|ll|r|r|r|}
\hline & & \multicolumn{1}{|c|}{ NFkb } & \multicolumn{1}{c|}{ miR31 } & \multicolumn{1}{c|}{ miR21 } \\
\hline NFkb & Pearson Correlation & 1 & $.858^{\prime \prime}$ & $.655^{\circ}$ \\
& Sig. (2-tailed) & & .000 & .000 \\
& $\mathrm{~N}$ & 28 & 28 & 28 \\
\hline miR31 & Pearson Correlation & $.858^{\prime \prime}$ & 1 & $.696^{\circ}$ \\
& Sig. (2-tailed) & .000 & & .000 \\
& $\mathrm{~N}$ & 28 & 28 & 28 \\
\hline miR21 & Pearson Correlation & $.655^{\circ}$ & $.696^{\prime \prime}$ & 1 \\
& Sig. (2-tailed) & .000 & .000 & \\
& $\mathrm{~N}$ & 28 & 28 & 28 \\
\hline
\end{tabular}

**. Correlation is significant at the 0.01 level (2-tailed).

\section{Figure 3}

Pearson correlation coefficient for the expression level of the miR-31, miR-21 and NF-KB. *Correlation is significant at the 0.05 level/** correlation is significant at the 0.01 level. 